\title{
A parapharyngeal meningioma presenting as a neck mass and multiple cranial nerve palsies
}

I Mohamad ${ }^{1}$, B Abdullah ${ }^{1}$, Z Idris², V R Naik ${ }^{3}$, V M K Bhavaraju 4

Ceylon Medical Journal 2011; 56: 73-74

\section{Case report}

A 20-year old Malay female presented with swelling at the angle of the mandible on the left side of 7 months duration. It was associated with neck discomfort, dysphagia and few episodes of aspiration. Examination showed a diffuse fixed swelling at the angle of mandible on the left side. It was non-tender and lymph node was not palpable. Multiple left cranial nerve palsies were elicited involving glossopharyngeal, vagus, accessory and hypoglossal nerves. Intraorally the left tonsil was medialized. ACT scan showed a left parapharyngeal tumour encasing the left carotid artery and left internal jugular vein (Figure 1). It measured $2.6 \mathrm{~cm} \times 4.6 \mathrm{~cm} \times 4.5 \mathrm{~cm}$. The cerebral angiogram showed tumour blush which was not suggestive of a glomus tumour. The feeding vessel was from ascending pharyngeal branch of the external carotid artery. ACT guided trucut biopsy revealed a meningothelial meningioma. She underwent subtotal tumour resection (Figure 2).

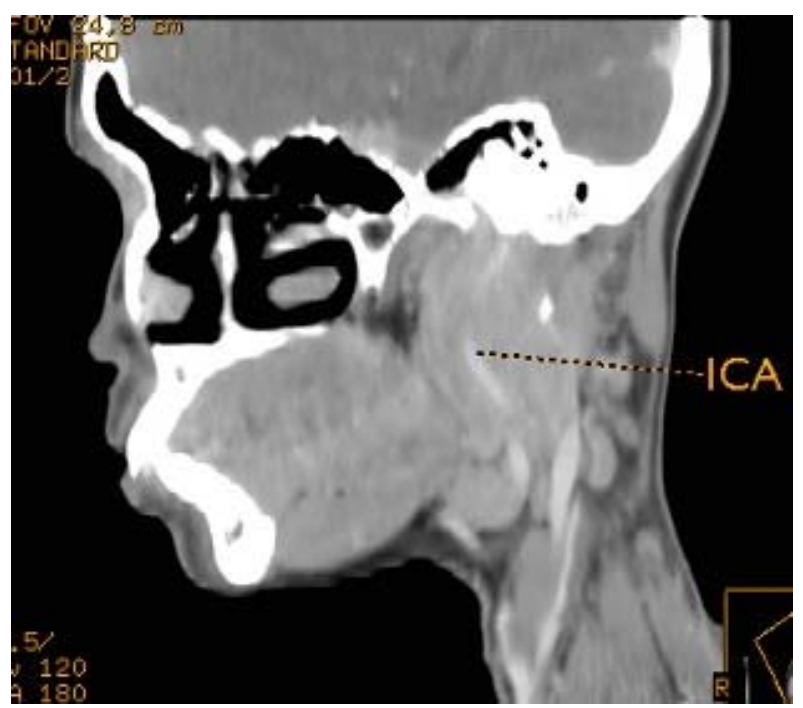

Figure 1. Contrast sagittal CT scan showing a left parapharyngeal mass encasing internal carotid artery.

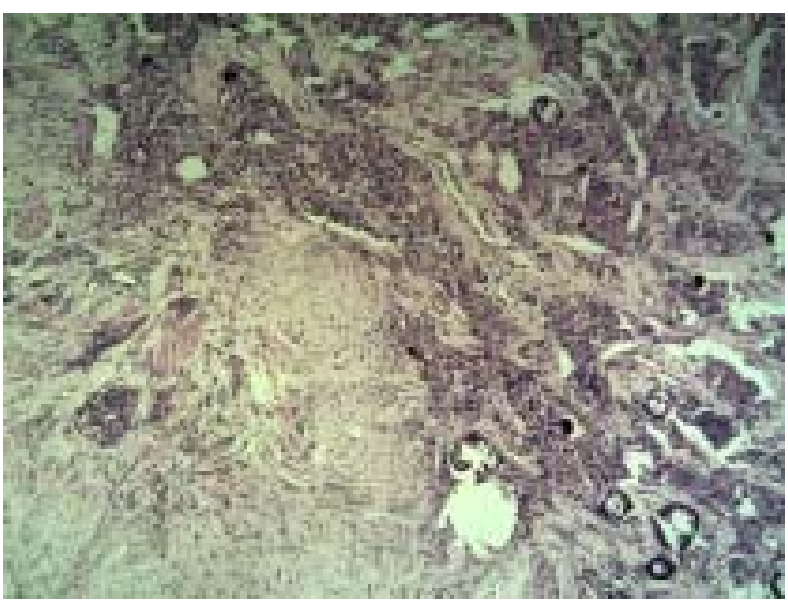

Figure 2. Tumour composed of both transitional and fibrous meningothelial elements with numerous psammoma bodies $(H \& E \times 10)$.

\section{Discussion}

Meningiomas tend to occur intracranially owing to the presence of meninges. In some rare circumstances, it can be found extracranially mainly in the structures adjacent to the cranial cavity. Extracranial meningiomas represent $2 \%$ of all meningiomas [1]. The lesion can be primary in nature or extension from an intracranial origin.

There are at least four mechanisms to explain the origin of parapharyngeal meningiomas: (a) extracranial extension from an intracranial tumour by way of neural foramina, (b) extracranial growth from the arachnoid within the cranial nerve sheaths, (c) extracranial growth from ectopic or embryonic arachnoid cell rest, and (d) distant metastases from intracranial meningioma [2,3]. The second and third mechanisms are more likely in this patient as the brain CT did not show abnormalities to suggest intracranial origin. Most of the parapharyngeal meningiomas are secondary from intracranial extension. Parapharyngeal space is an uncommon site for primary meningioma.

In cases of benign intracranial meningiomas, the completeness of the resection is the major prognostic factor determining the outcome [4]. As an adjunct

${ }^{1}$ Department of Otorhinolaryngology, ${ }^{2}$ Department of Neurosciences, ${ }^{3}$ Department of Pathology, and ${ }^{4}$ Department of Nuclear Medicine, Radiotherapy and Oncology, School of Medical Sciences, Universiti Sains Malaysia, 16150 Kota Bharu, Kelantan, Malaysia.

Correspondence: BA, e-mail <baharudin@kb.usm.my>. Received 12 July and revised version accepted 30 October 2010. Competing interests: none declared. 
treatment, external beam radiotherapy has been shown to control the residual microscopic disease after definitive surgery. In addition, radiation therapy is also used to control grade III meningiomas or as a palliative modality in inoperable or elderly patients $[5,6]$.

\section{References}

1. Kershisnik M, Callender DL, Batsakis JG. Extracranial, extraspinal meningiomas of the head and neck. Annals of Otology, Rhinology and Laryngology 1993; 102: 967-70.

2. Imes RK, Monteiro ML, Hoyt WF. Optic nerve meningioma with enophthalmos. Journal of Clinical NeuroOphthalmology 1984; 4: 213-5.
3. Nager GT, Heroy J, Hoeplinger M. Meningiomas invading the temporal bone with extension to the neck. American Journal of Otolaryngology 1983; 4: 297-324.

4. Mathiesen T, Lindquist C, Kihlstrom L, Karlsson B. Recurrence of cranial base meningiomas. Neurosurgery 1996; 39: 2-7.

5. Rosenberg LA, Prayson RA, Lee J, et al. Long term experience with World Health Organization grade III (malignant) meningiomas at a single institution. International Journal of Radiation Oncology Biology Physics 2009; 74: 427-32.

6. Milosevic MF, Frost PJ, Laperriere NJ, et al. Radiotherapy for atypical or malignant intracranial meningioma. International Journal of Radiation Oncology Biology Physics 1996; 34: 817. 